\title{
Lipomas of the Colon: A Surgical Challenge
}

\author{
Ketan Vagholkar*, Mahendra Bendre \\ Department of Surgery, Dr. D. Y. Patil Medical College, Navi Mumbai, India \\ Email: "kvagholkar@yahoo.com \\ Received 5 February 2014; revised 3 March 2014; accepted 24 March 2014 \\ Copyright (C) 2014 by authors and Scientific Research Publishing Inc. \\ This work is licensed under the Creative Commons Attribution International License (CC BY). \\ http://creativecommons.org/licenses/by/4.0/ \\ (c) (i) Open Access
}

\begin{abstract}
Lipomas of the colon are rare benign tumors second only to adenomas in their incidence. They are devoid of malignant potential. They usually become manifest by way of complications ranging from bleeding to acute intestinal obstruction. Radiological investigations may help to confirm the diagnosis in a significant number of non-emergent situations. However, confirmation of diagnosis is invariably done at the time of therapeutic intervention. A proper choice of therapeutic option between endoscopic or open surgical intervention needs to be made for a good outcome.
\end{abstract}

\section{Keywords}

Lipoma; Colon; Complications; Treatment; Endoscopic; Surgical

\section{Introduction}

Lipomas are benign non epithelial tumors which are found to develop in any part of the gastrointestinal tract. The commonest site for these tumors happens to be the colon. The incidence of colonic lipoma varies approximately from $0.2 \%$ to $4.4 \%$ [1]. Study of articles published on the topic in PubMed and Google scholar revealed that the literature on the topic is fragmented mostly in the form of case reports.

A review of the pathology, clinical presentation, diagnostic challenges and management of colonic lipomas is presented.

\section{Etiopathogenesis}

Lipoma is rightly described as a ubiquitous tumor. Even the gut is not spared. In the gut the colon happens to be the commonest site for occurrence of this benign tumor. There are no specific predisposing factors or associated epidemiological factors for lipomas of the colon. The age at which these tumors are discovered is usually the sixth decade of life. However these lesions may even be seen in younger individuals. They are more common in women with predilection for the right side of the colon in women as compared with predilection for the left side

\footnotetext{
*Corresponding author.
} 
of the colon in men [1]. The size is variable varying from a few millimeters to as large as $30 \mathrm{cms}$. Most of them are usually situated submucosally [2]. However subserosal lipomas are also described [3] (Figure 1). Occasional association of a colonic lipoma with retroperitoneal sarcoma has been reported. Grossly the tumors are well circumscribed, soft and lobulated masses. They may be pedunculated or sessile. This morphological feature may decide the pattern of presentation of these tumors. The tumor is slow to grow and may assume a large size depending upon the direction of growth. This explains the variability in symptoms [1].

\section{Natural History}

The tumor grows at a very slow pace. If the growth is towards the luminal side then these become symptomatic at an early stage. However, if they grow towards the serosa side then the presentation may be delayed. Episodes of per rectal bleeding, intestinal obstruction ranging from the sub-acute to acute form have been described [2] [3]. Pedunculated lipomas usually serve as nidus for intussusception to develop. Literature is a bound with case reports of intussusception being one of the commonest pathological phenomenon leading to diagnosis of these tumors [4]-[7]. Malignant change in lipomas of the colon has not been described [8]. Auto amputation of a sub mucosal lipoma with expulsion per rectally has been described [9]-[11].

\section{Clinical Presentation}

Colonic lipomas are notorious for their clinical latency and variability of presentations [12]. Location and size of the tumors largely determines the pattern of clinical presentation. Lipomas situated in the subserosal layer usually manifest late with features of an abdominal lump. Symptoms of obstruction may not always be present. Bleeding is absent as the mucosal lining is still not breached. However tumors which are placed submucosally are early to manifest [13] [14]. Intermittent attacks of colicky pain, bleeding and features of obstruction are commonly encountered. The tumor will invariably serve as an apex for intussusception to occur. In such cases features of acute intestinal obstruction are usually seen. Size is an important determinant of symptomatology. Usually tumors greater than $4 \mathrm{cms}$ will manifest in some way or the other. Until they reach this size they remain clinically dormant [14].

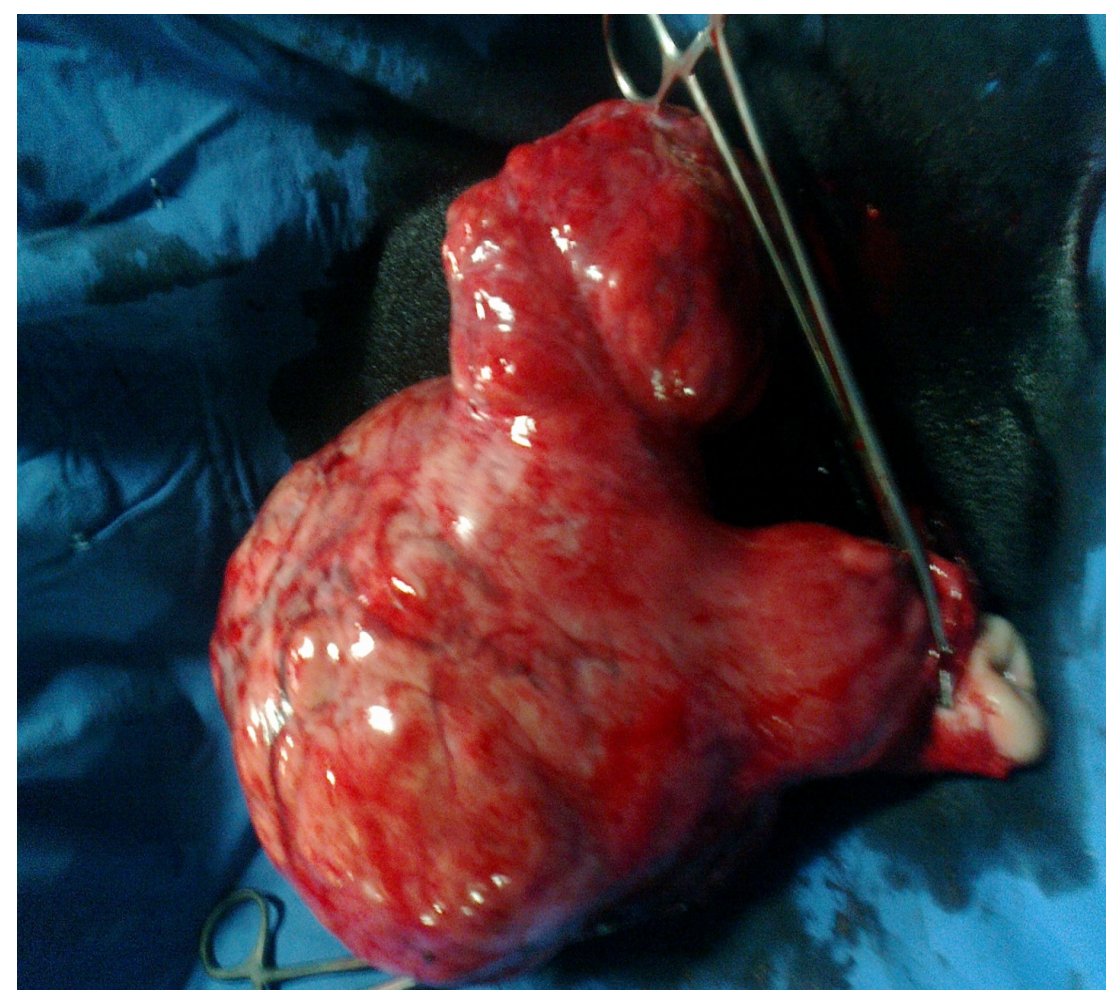

Figure 1. A gross specimen of a resected large lipoma of the colon. 
Since all the clinical features closely mimic malignancy, the greatest challenge is to confirm the diagnosis [13] [14]. Clinically it may pose a great diagnostic challenge to differentiate between the two. It is therefore prudent to be quick and prompt in carrying out relevant investigations to confirm the diagnosis.

\section{Diagnosis}

Hematological investigations will not be of much help in most cases. Tumor markers such as CEA will not be raised in lipomas.

There could be a fall in the hemoglobin levels due to chronic bleeding. Barium enema can be of great help. However the diagnostic role of barium enema is restricted to non-obstructed cases only. Endoscopy is a more promising investigation as it allows direct visualization of the lesion as well as permits a biopsy to be taken [15]-[17]. This helps in preoperative tissue diagnosis. Various peculiar signs may be picked on a barium enema and endoscopy. Squeeze sign on barium enema is one in which a well-defined spherical radiolucent filling defect which changes its size and shape with peristalsis is seen [17]. Colonoscopy allows a detailed appraisal of the lesion. A EUS examination can also be done at the same time. It typically demonstrates a hyper echoic lesion originating in the submucosal layer [15].

The site and nature of the growth is well determined by colonoscopy. The growth is typically polypoidal and yellowish in color. It can be easily indented. On withdrawing the forceps the growth springs back to its original shape. This is called the cushion sign. Grasping the mucosa with a forceps causes a tenting effect which is classically designated as the tent sign [1] [17] [18].

Though colonoscopy allows direct visualization of the tumor the diagnostic yield by way of an adequate tissue biopsy may at times be limited. The biopsy may not be adequate to reach the depths of the tumor well below the mucosal layer. In such cases the biopsy report will be equivocal making open biopsy at the time of surgery mandatory. Even a biopsy report of a benign tumor needs to be studied in great detail after the specimen has been removed. This is because a thorough study of the resected specimen for malignant foci is mandatory in order to achieve a standard of safe surgical practice. In an acute presentation barium enema and endoscopy are not feasible and hence only a CT scan will be of help in the diagnosis.

Contrast enhanced CT scan of the abdomen is a useful adjunct in the diagnosis [16]. It reveals the exact location and size of the tumor with respect to the part of the involved colon, the plane in which it is located (sub mucosal or subserosal), evidence of malignancy with respect to any sort of infiltration and status of the lymph nodes. Lipomas typically are seen as masses compromising the colonic lumen with characteristic fatty densitometry value.

\section{Treatment}

Surgical resection and endoscopic resection are the two therapeutic options available [19]-[21]. A proper assessment needs to be done before making a choice of the option. For uncomplicated pedunculated sub mucosal lipomas less than $4 \mathrm{cms}$ in size endoscopic option can be exercised [19]. Care has to be taken to ensure that the peduncle is clear of the tumor grossly. For sessile tumors endoscopic clearance may at times be inadequate [20] [21]. In such cases open surgical resection is preferable.

For patients presenting with complications of obstruction or intussusception it is always a safe practice to resort to open surgical resection [22] [23]. This enables adequate resection of the specimen as well as a proper formal exploration of the peritoneal cavity to rule out the slightest possibility of malignancy. If suspicious findings are encountered the best option is to get a frozen section done. As the colon happens to be unprepared in emergency situations, a segmental colonic resection with a proximal stoma is advisable in order to ensure healing of the anastomosis [24]. This stoma can then be closed at a later date after ensuring complete healing of the anastomosis. For patients presenting with a lump as in the case of large lipomas open surgical exploration is advisable [25]. Segmental resection of the affected colon is advisable. If the patient is not in an obstructed state then preoperative bowel preparation can safely be done. In such cases there is no need for creation of a proximal stoma.

\section{Conclusion}

Clinical latency and variability in clinical presentation are typical of colonic lipomas. Both endoscopic as well as 
surgical resection is excellent options. Uncomplicated, pedunculated submucosal lipomas are best suited for endoscopic resection. However, lipomas at any location or of any type and size with supervening complications are best dealt with open surgical intervention.

\section{Acknowledgements}

I would like to thank Mr. Parth K. Vagholkar for his help in typesetting the manuscripts.

\section{References}

[1] Vecchio, R., Ferrara, M., Mosca, F., Ignoto, A. and Latteri, F. (1966) Lipomas of the Large Bowel. European Journal of Surgery, 162, 915-919.

[2] Montes Teves, P., Salazar Ventura, S. and Ramos Barrientos, M. (2007) Giant Colonic Lipoma as a Cause of Lower Digestive Hemorrhage. Report of a Case. Revista de Gastroenterología del Perú, 27, 307-309.

[3] Rogy, M.A., Mirza, D., Berlakovich, G., Winkelbauer, F. and Rauhs, R. (1991) Submucous Large Bowel Lipomas-Presentation and Management. An 18 Year Study. European Journal of Surgery, 157, 51-55.

[4] Chiang, J.M. and Lin, Y.S. (2008) Tumor Spectrum of Adult Intussusception. Journal of Surgical Oncology, 98, 444447. http://dx.doi.org/10.1002/jso.21117

[5] James, J. and Strauss, P.N. (2012) Complicated Colonic Intussusception. Journal of Emergencies, Trauma and Shock, 5, 188-189. http://dx.doi.org/10.4103/0974-2700.96493

[6] Howard, N., Pranesh, N. and Carter, P. (2012) Colo-Colonic Intussusception Secondary to a Lipoma. International Journal of Surgery Case Reports, 3, 52-54. http://dx.doi.org/10.1016/j.ijscr.2011.10.011

[7] Martin, P., Sklow, B. and Adler, D.G. (2008) Large Colonic Lipoma Mimicking Colon Cancer and Causing Colonic Intussusception. Digestive Diseases and Sciences, 53, 2826-2827. http://dx.doi.org/10.1007/s10620-008-0202-5

[8] Yeom, J.O., Kim, S.Y., Jang, E.C., Yu, J.V., Chang, E.D. and Cho, Y.S. (2013) Colonic Lipomas Covered by Hyperplastic Epithelium: Case Report. World Journal of Clinical Cases, 1, 124-127.

http://dx.doi.org/10.12998/wjcc.v1.i3.124

[9] Gupta, A.K. and Mujoo, V. (2003) Spontaneous Auto Amputation and Expulsion of Intestinal Lipoma. Journal of the Association of Physicians of India, 51, 833.

[10] Chahri, N., Querol, V., Ballesta, E., Marti, M. and Garrigo, J. (2013) Spontaneous Expulsion of a Large Left Colon Lipoma. Revista Espanola de Enfermedades Digestives, 105, 501-502. http://dx.doi.org/10.4321/S1130-01082013000800013

[11] Jeong, H.K., Cho, S.B., Seo, T.J., Lee, K.R., Lee, W.S., Kim, H.S. and Joo, Y.E. (2011) Auto Amputation of a Giant Colonic Lipoma. Gut Liver, 5, 380-382. http://dx.doi.org/10.5009/gnl.2011.5.3.380

[12] Djolai, M.A., Andrejic, B.M. and Ivanov, D.D. (2013) Lipoma of the Sigmoid Colon. Vojnosanit Pregl, 70, $319-321$. http://dx.doi.org/10.2298/VSP1303319D

[13] Bardaji, M., Roset, F., Camps, R., Sant, F. and Fernandez-Layos, M.J. (1998) Symptomatic Colonic Lipoma: Differential Diagnosis of Large Bowel Tumors. International Journal of Colorectal Disease, 13, 1-2. http://dx.doi.org/10.1007/s003840050122

[14] Bahadursingh, A.M., Robbins, P.L. and Longo, W.E. (2003) Giant Submucosal Sigmoid Colon Lipoma. American Journal of Surgery, 186, 81-82. http://dx.doi.org/10.1016/S0002-9610(03)00111-9

[15] Shepherd, B.D., Merchant, N., Fasig, J. and Schwartz, D.A. (2006) Endoscopic Ultrasound Diagnosis of Pelvic Lipoma Causing Neurologic Symptoms. Digestive Diseases and Sciences, 51, 1364-1366. http://dx.doi.org/10.1007/s10620-006-9106-4

[16] Moussa, D.M., Tee, M., Khan, A.U. and Selvasekar, C.R. (2013) Computerized Tomography Providing Definitive Diagnosis of Colonic Lipoma: A Case Series. Surgical Laparoscopy, Endoscopy \& Percutaneous Techniques, 23, e232e234.

[17] Mantzoros, I., Raptis, D., Pramateftakis, M.G., Kanellos, D., Psomas, S., Makrantonakis, A., Tsachalis, T. and Angelopoulos, S. (2011) Colonic Lipomas: Our Experience in Diagnosis and Treatment. Techniques in Coloproctology, 15, S71-S73.

[18] Koktener, A. and Erden, A. (2007) Usefulness of Virtual Colonoscopy in the Diagnosis of Symptomatic Large Colonic Lipomas. Australian Radiology, 51, 144-146.

[19] Castro, E.B. and Stearns, M.W. (1972) Lipoma of the Large Intestine: A Review of 45 Cases. Diseases of the Colon \& Rectum, 15, 441-444. http://dx.doi.org/10.1007/BF02642650

[20] Kim, C.Y., Bandres, D., Tio, T.L., Benjamin, S.B. and AI Kawas, F.H. (2002) Endoscopic Removal of Large Colonic 
Lipomas. Gastrointestinal Endoscopy, 55, 929-931. http://dx.doi.org/10.1067/mge.2002.124098

[21] Pfeil, S.A., Weaver, M.G., Abdul Karim, F.W. and Yang, P. (1990) Colonic Lipomas: Outcome of Endoscopic Removal. Gastrointestinal Endoscopy, 36, 435-438. http://dx.doi.org/10.1016/S0016-5107(90)71110-8

[22] Son, D.N., Jung, H.G. and Ha, D.Y. (2013) Laparoscopic Surgery for an Intussusception by a Lipoma in the Ascending Colon. Annals of Coloproctology, 29, 80-82. http://dx.doi.org/10.3393/ac.2013.29.2.80

[23] Nebbia, J.F., Cucchi, J.M., Novellas, S., Bertrand, S., Chevallier, P. and Bruneton, J.N. (2007) Lipomas of the Right Colon: Report of Six Cases. Clinical Imaging, 31, 390-393. http://dx.doi.org/10.1016/j.clinimag.2007.06.021

[24] Vagholkar, K.R. (2001) Healing of Anastomosis in the Gastrointestinal Tract: Retrospective Study of 35 Cases. Bombay Hospital Journal, 43, 269-280.

[25] Nallamothu, G. and Adler, D.G. (2011) Large Colonic Lipomas. Journal of Gastroenterology and Hepatology, 7, 490492. 